\title{
Seasonal Weather and its Prediction*
}

\section{By Sir GILbert T. WALKer, c.s.I., F.R.S.}

$\mathrm{T}$ HE economic importance of seasonal weather is obvious to most men who have lived in the tropics, and its scientific problems are full of interest. Unfortunately there is an additional motive for study, the threat of dangers ahead. For the difficulties of long-range forecasting are not in general adequately recognised, so that some of the most progressive countries in the world are inclined to make predictions on an insecure basis; their technical staff does not realise that though the prestige of meteorology may be raised for a few years by the issue of seasonal forecasts, the harm done to the science will inevitably outweigh the good if the prophecies are found unreliable.

In a country where conditions are so changeable from day to day as they are in England, it is natural that we should think in terms of wet or fine days rather than of wet or dry periods; but in the greater part of the British Empire the different seasons are much more sharply defined, and so their dominant features stand out more clearly. Also the variability of their seasons from year to year is in general materially greater than here.

In agricultural countries in which a failure of the rains involves a national calamity, the desirability of making preparations in advance led long ago to efforts at prediction; and the demand has been so great that the supply has been forthcoming before its quality would bear the most cursory examination. The causes of unusual seasons seem hopelessly obscure to the layman; and hence primitive ideas, surviving in the depth of our natures from untold ages of magical practices, still come to the surface in connexion with it. The almost universal idea that weather must repeat itself after a certain number of years finds its origin, I imagine, ultimately in the ancient belief in the control of our affairs by the heavenly bodies with their definite cycles-a belief which clearly shows itself in the supposed influence of the moon on the weather. Be that as it may, the faith in periods is so deep-seated that even in scientific discussions the ordinary tests for validity are very often ignored : more than once I have seen in journals

* From the presidential address before Section A (Mathematical and Physical Sciences) of the British Association at Leicester, delivered on September 8. of repute the artless remark of an author that if he were to limit his methods to those which would satisfy the criteria of reality, he would obtain few results of interest!

It will be convenient if I may here introduce a technical phrase. If we have series of values of two factors the variations of which are connected, there will be a certain proportion of the variations of each which are associated with those of the other, and this proportion is called the correlation coefficient between the series. If it is nearly unity the numbers vary closely together; if it is small

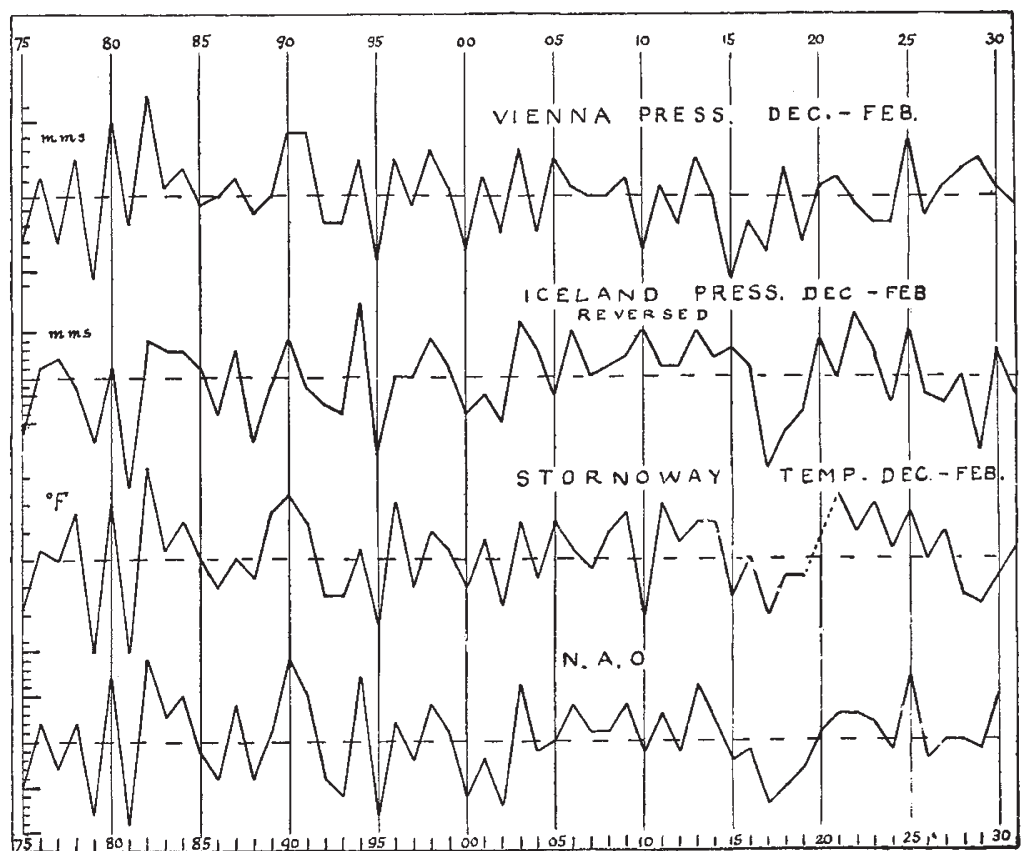

FIG. 1. N. Atlantic oscillation.

there is little relationship between them; and if it approaches -1 the relationship is close, but one series goes up when the other goes down.

Let us now consider some of the results of the analysis of seasonal features. It has long been known that in the North Atlantic Ocean there are two types of winter. In one, pressure is high near the Azores and south-west Europe, and low in Iceland, while temperatures are high in northwest Europe ; in the other type, all these features are reversed. (See the three upper graphs in Fig. 1.) Let us plot the variations in successive winters, December to February, of the quantities which increase together, such as Vienna pressure and Stornoway temperature, and also of the quantities which decrease when the former increase, such as Iceland pressure, reversing the latter so as to secure similarity of the graphs. We could then draw a graph which is the mean of all, and could 
regard it as expressing the variations of the North Atlantic fluctuation as a whole. (See the lowest. graph of Fig. 1.)

Now instead of graphs we actually use numbers. Having found by preliminary investigation the
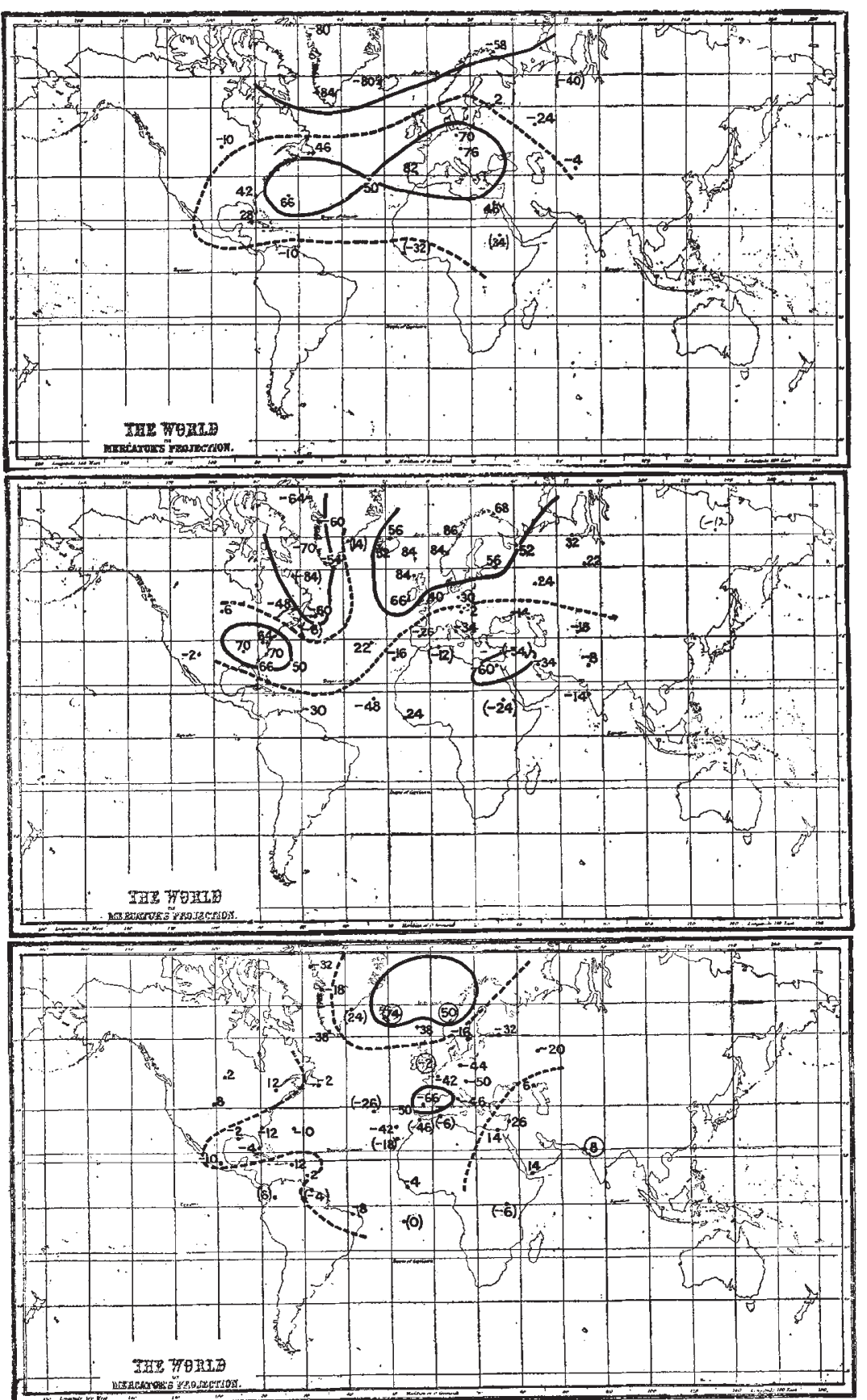

Frg. 2 Relations of N. Atlantic oscillation with contemporary pressure, temperature and rainfall of December to February. Numbers based on series shorter than 30 years are in brackets ; those for areas are in circles.

stations which are most representative, we calculate the figures in successive years for the North Atlantic oscillation as a whole, and then work out the correlation coefficients of this with the pressures, temperatures and rainfalls of all the places in which we are interested. These coefficients are plotted in Fig. 2, in the top chart of which we see that the rise of pressure with a positive fluctuation is greater so far east as Vienna and so far west as the Bermudas than it is at the Azores. There is also to be seen in the second chart conspicuous warmth in the east of the United States as well as in north-west Europe, and marked cold to the southeast of the Mediterranean as well as along the north-east of North America. On rainfall, in the lowest chart, the influence is less widespread.

The North Pacific Ocean, in spite of its limited access to the Arctic seas, is subject to fluctuations very similar to those of the North Atlantic. A similar treatment shows that increased pressure gradients go with high temperature to the north-east and south-west, and low temperature to the north-west and south-east.

The largest known system of related seasonal weather is that called the "southern oscillation' (or 'southern fluctuation'), which has features in the southern sumimer of December-February (Fig. 3) somewhat different from those of the southern winter of June-August. At both times of the year the fluctuation is called positive when pressure is high in the southern Pacific and low in the Indian Ocean, and temperature is mostly low in the tropics; but the economic importance is in connexion with rainfall, for the fluctuation has a correlation coefficient of more than 0.8 with the summer rainfall of north-east Australia, more than 0.7 with the monsoon rainfall of India and with the Nile floods, $0 \cdot 6$ with the rainfall of large areas in South America, and more than 0.5 with that of a region in South Africa.

A surprising fact comes out on comparing the numerical series giving the characteristics of the summer and winter values of this fluctuation, the control of the southern winter on the succeeding summer being expressed by a coefficient of 0.82 . 
The immediate effect of this is that numerical values of the winter oscillation give us a means of predicting three months in advance, at any rate approximately, the summer values of the oscillation and therefore of the pressure, temperature and rainfall associated with them. We can plot the relationships of the values of the pressure, temperature and rainfall of December to February, with the numbers indicating the fluctuation of the previous June to August : and we get a diagram like Fig. 3 but with coefficients reduced to about four-fifths of the size. These express relationships which have held for about fifty years, and show that we have arrived, not at a mathematical figment, but at a physical reality that should have commercial value.

This method of prediction can be improved on by study of the relationships of individual areas. For example, the coefficient of 0.64 of rainfall of north-east Australia with the oscillation of the previous winter becomes 0.79 , when we base it on previous pressure at Honolulu, Port Darwin and South America; a comparisun of the actual rainfall with that given by the formula is shown in Fig. 4. Similarly, the 0.56 of South Africa becomes 0.72 . But a certain amount of the improvement effected in this way by selecting the biggest factors is bound to be fictitious, even when there appear to be adequate independent reasons for thinking that the relationships are real; and, if this precaution is ignored, the more promising the formula, as indicated by the closeness of its apparent relationship, the greater is the likelihood of disappointment.

It must be admitted that a real control of 0.7 by previous conditions is about as good as is now available for forecasting, and the difference between the actual and the forecast amounts will still be considerable; so predictions can only be issued with restraint if public confidence is to be won. The natural consequence is silence, except when the indications are markedly favourable or unfavourable.
Let us now turn from the academic to the practical, and see how far these theoretical methods justify themselves in actual experience. I believe that the earliest regular seasonal forecasts based on meteorological instead of astro-
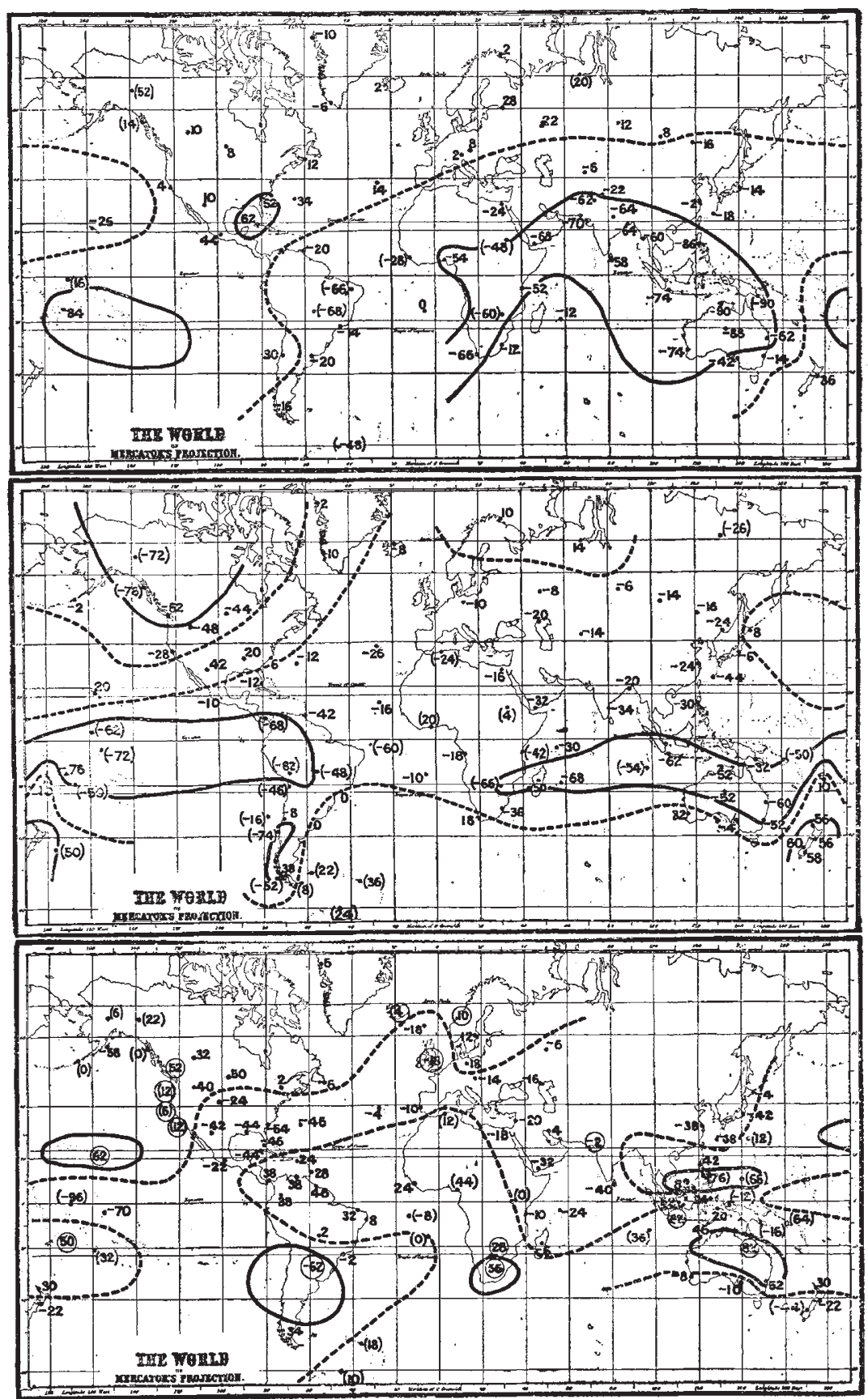

FIG. 3. Relations of southern oscillation of December to February with contemporary pressure, temperature and rainfall.

logical data were those of the Indian monsoon of June-September, started half a century ago in India by H. F. Blanford, and depending mainly for their success on the ill-effect upon the monsoon of excessive winter or spring snowfall in the 
Himalayas. Eliot continued the monsoon forecasts from 1887 until 1903, but data in those days were scanty; he attempted far too much detail, his mode of expression was somewhat pontifical, and the newspapers became sarcastic; so latterly he sought immunity from criticism by printing the forecasts as confidential documents. The increase of staff for which Eliot fought, and the gradual introduction of statistical methods in India, have undoubtedly led to improvement; but as we have seen, it is much easier to predict the rainfall of December-February than that of June September, and the length of the series of Indian data is not yet great enough to give complete reliability. After careful scrutiny, I estimate that of the forecasts issued before the monsoon periods from 1905 until 1932 two-thirds were correct; but I consider that this is not good enough and that we have been. too ambitious.

Happily, in Southern Rhodesia, which in 1922 adopted statistical methods similar to those of India with only twenty-four years of data to work upon, the results have been eminently satisfactory. Out of eleven years since publication was begun, generally. Thus one of the Californian hydroelectric companies makes its own forecasts, because it may spend four million dollars more for crude oil in a dry than in a wet year.

Undeterred by the difficulties, G. F. McEwen, of the Scripps Institution of Oceanography in Califormia, has for some time been forecasting rainfall by empirical methods, and at first attained considerable success, largely on the basis of a short series of ocean temperatures. These, however, as he has recognised, have not of late made good their early promise, and new methods have been adopted.

In Europe the only seasonal forecasts known to me that have a scientific foundation, and have been made for a number of years, are those of Sweden and Russia. They are not over-ambitious and have met with gratifying success.

We may now pass to the consideration of improvements in our methods, and the fundamental question at once arises: What is the physical cause of seasonal fluctuations? We should naturally look for it in variations in the energy received from the sun, and it is surprising that an increase in solar activity as measured by sunspots produces a slight decrease in the circulations in the North Atlantic and the North Pacific. In the southern fluctuations the tendency of numerous spots is to produce positive values, but even there the biggest seasonal correlation coefficient is only 0.26 , which is much too small to provide the explanation that we seek.

In order to ascertain whether daily pressures are produced by FIG. 4. N.E. Australian rainfall, October to April.

there have been only eight in which a departure of more than $3 \mathrm{in}$. was given by the formula, and in seven of these the character was correctly indicated.

At Batavia, the efficient Dutch observatory under Braak started in 1909 to issue forecasts founded on the simple rule that low pressure from January until June was followed by abundance of rain from July until December. The rule demanded a more complete persistence of pressure than actually prevails, and in 1927 Berlage adopted a formula based on three local conditions, together with data of the rare rains of northern Peru : this gives, on paper, a relationship of more than $0 \cdot 8$.

When we turn from the tropical and subtropical to the temperate.regions, where the persistence of conditions is in general conspicuously smaller, we must expect greater difficulties in making longrange forecasts. In America the relations between weather and crops have probably been worked out more scientifically than in any other country, so that the commercial value of reliable prediction has long been recognised; and not only by farmers, but also by those interested in water supply, in power schemes, in transport and in commerce short-lived emanations from the sun, like those which produce magnetic storms, tabulations of the relationships between daily and weekly, as well as monthly and seasonal, values at distant places have been made; for if the daily values over the earth are controlled from outside, there will be close parallelism between these daily and weekly pressures. But the result has been definitely negative.

Being forced off short-lived phenomena, we search for an explanation in terms of slowly changing features; and the variations from year to year in both $(a)$, the amount of pack ice in the antarctic sea, and $(b)$, the temperature of the Pacific Ocean, force themselves on our attention. But data from the South Orkneys and Samoa give no support.

A moment's reflection will convince us that there is ample scope for new developments. There are variations of rainfall over large areas, which are scarcely affected by the three big fluctuations; and there are indications of pressure fluctuations in the antarctic which have not as yet been adequately explored. Thus any who may be tempted to tackle the problems will find no lack of material. 